\title{
Population structure and linkage disequilibrium of ICRISAT foxtail millet (Setaria italica (L.) P. Beauv.) core collection
}

\author{
M. Vetriventhan · Hari D. Upadhyaya • \\ C. R. Anandakumar $\cdot$ S. Senthilvel $\cdot$ \\ R. K. Varshney $\cdot$ Heiko K. Parzies
}

Received: 29 July 2013/ Accepted: 8 December 2013

(C) Springer Science+Business Media Dordrecht 2013

\begin{abstract}
Use of diverse germplasm is a key factor which allows high level of resolution due to extensive recombination in the history. Therefore, population used in association mapping should posses as many phenotypes as possible. One of the methods to obtain most of the phenotypes is to construct the core collection. The ICRISAT foxtail millet core collection consisting of 155 accessions was genotyped using 72 simple sequence repeat (SSR) markers to investigate the genetic diversity, population structure and linkage disequilibrium (LD). A high degree of molecular diversity among the accessions was found, with an
\end{abstract}

M. Vetriventhan · H. D. Upadhyaya $(\bowtie)$.

S. Senthilvel · R. K. Varshney

International Crops Research Institute for the Semi-Arid

Tropics (ICRISAT), Patancheru 502 324,

Andhra Pradesh, India

e-mail: h.upadhyaya@cgiar.org

C. R. Anandakumar

Agricultural College and Research Institute, Tamil Nadu Agricultural University (TNAU), Madurai 625 104,

Tamil Nadu, India

Present Address:

S. Senthilvel

Directorate of Oilseeds Research (DOR), Rajendranagar, Hyderabad 500 030, Andhra Pradesh, India

H. K. Parzies

Institute of Plant Breeding, Seed Science and Population Genetics, University of Hohenheim, Fruwirthstr. 21,

70599 Stuttgart, Germany average of 16.69 alleles per locus. STRUCTURE analyses classify the accessions into four subpopulations (SP) based on SSR allelic diversity. The Neighbor joining clustering and the principal coordinate analysis were in accordance with the racial classification. The distribution of molecular genetic variation among and within the four SP and three races showed high degree of variability within each group, and low level of genetic distance (GD) among the groups. LD decay of $<40 \mathrm{cM}$ of GD in foxtail millet core collection was observed, which suggests that it could be possible to achieve resolution down to the $40 \mathrm{cM}$ level. From this investigation, it is evident that the foxtail millet core collection developed at ICRISAT is very diverse and could be a valuable resource for trait association mapping, crop breeding and germplasm management.

Keywords Analysis of molecular variance .

Core collection - Foxtail millet - Genetic

diversity $\cdot$ Linkage disequilibrium $\cdot$ Population

structure $\cdot$ Simple sequence repeat

\section{Introduction}

Small millets are gaining importance because of their wider adaptability to drought and varied soil and environmental conditions, and nutritional benefits. Foxtail millet (Setaria italica (L.) P. Beauv.) $(2 n=18)$, is one among the small millets, distributed widely around 
warm and temperate regions of Asia, Europe, North America, Australia and North Africa (Zhang et al. 2012). It is an ancient crop, its domestication in China dates back to 8,700 years ago (Lu et al. 2009), has greatly contributed to human civilizations both in Asia and Europe (Barton et al. 2009). Foxtail millet is as an important food and fodder crop in semi-arid tropics, particularly in changing climate. It produces substantial yield under varied environmental conditions, remains an essential food for home consumption in parts of India, China, Korea and Japan (Austin 2006). Taxonomically, foxtail millet is comprised of two subspecies, S. italica subsp. italica and subsp. viridis, and the wild ancestor of foxtail millet is S. viridis (Kihara and Kishimoto 1942; Li et al. 1945). Prasada Rao et al. (1987) have recognized three races of foxtail millet (moharia, maxima and indica) based on the morphological features.

Its relatively small genome size $(\sim 400 \mathrm{Mb})$ (Bennetzen et al. 2012), inbreeding nature, short duration, $\mathrm{C}_{4}$ nature, and wide geographic distribution and adaptability, make it an ideal model for grass functional genomics to investigate plant architecture, genome evolution, drought tolerance and physiology in the bioenergy grasses (Doust et al. 2009; Wang et al. 2010; Li and Brutnell 2011). A diversified germplasm collection plays a key role in both breeding and genomic research for any crop species. The International Crops Research Institute for the Semi-Arid Tropics (ICRISAT), Patancheru, India has 1,534 foxtail millet accessions from 26 countries. To make use of this, Upadhyaya et al. (2008) developed a core collection consisting of 155 accessions, which represent $10.51 \%$ of 1,474 foxtail millet germplasm accessions conserved in ICRISAT genebank covering 23 countries. The entire germplasm collection of 1,534 accessions in foxtail millet is not large when compared with other crops like sorghum in ICRISAT Genebank (about 38,000 accessions), yet it is large in view of very low research priorities for neglected and under-utilized crops like foxtail millet. Moreover, this core collection can be evaluated extensively at a relatively low cost and information derived could be used a guide toward efficient utilization of the entire collection (Upadhyaya et al. 2008). Further, assessment of genetic diversity, population structure and linkage disequilibrium (LD) of foxtail millet core collection could provide essential information for germplasm management, association mapping and crop improvement.
The phenotypic variations of many complex traits of agronomic importance are influenced by many genes, environment and interaction between genes and environment (Holland 2007). Linkage analysis and association mapping are the two most commonly used tools for dissecting complex traits (Zhu et al. 2008). Association mapping is an effective approach to detect QTL, if information on population structure and LD is available. Association mapping has been proved to be an effective approach to mine the elite genes in germplasm resources (Zhang et al. 2011), has been successfully applied in several crops (Agrama et al. 2007; Malosetti et al. 2007; Zhao et al. 2007; Murray et al. 2009; Wen et al. 2009; Borba et al. 2010; Liu et al. 2010; Neumann et al. 2011; Dodig et al. 2012; Upadhyaya et al. 2012a, b). One of the foremost factors is use of diverse germplasm in association mapping panel, which allows high level of resolution due to extensive recombination in the history (Wang et al. 2008). Therefore, choice of germplasm is the preliminary factor which determines the resolution of association mapping. Population used in association mapping should posses as many phenotypes as possible (Flint-Garcia et al. 2005). To achieve this, one of the methods to obtain most of the phenotypes is to construct the core collection (Zhang et al. 2011). A core collection (Frankel 1984) consists of a limited set of accessions (about $10 \%$ ) derived from an existing germplasm collection, chosen to represent the genetic spectrum in the whole collection. In a species for which a core or mini core (Upadhyaya and Ortiz 2001) collections have been established, the core/mini core would be the ideal material for association mapping (Whitt and Buckler 2003).

Presence of population structure in the association panel, which is a division of the population into distinct subgroups related by kinship, leads to false positive association in association mapping ( $\mathrm{Yu}$ and Buckler 2006; Zhu et al. 2008). Resolution of association studies depends on the structure of LD across the genome (Remington et al. 2001), low level of LD could lead to impractical whole-genome scanning because of the excessive number of markers required (Kruglyak 1999). Therefore, detailed information on population structure and extent of LD within the population are of fundamental importance for association mapping (Stich et al. 2005). Only a few previous researches on genetic diversity and population structure have been reported in foxtail millet. Wang et al. (2012) reported four subgroups in 250 landraces, which are in good 
accordance with eco-geographical distribution in China. Hirano et al. (2011) did population structure analysis by transposon display, which classified foxtail millet landraces into eight clusters that are closely related with geographic origins and suggest a monophyletic origin of foxtail millet domestication. Liu et al. (2011) investigated the population structure of foxtail millet and identified six groups, which matches with their pedigree information, in general, but not with their geographic origins.

In this study, a foxtail millet core collection (Upadhyaya et al. 2008) consisting of 155 accessions was used. The abundant variation of the foxtail millet core collection provides an important reservoir of genetic diversity and potential sources of beneficial alleles for its improvement (Upadhyaya et al. 2008). However, the knowledge on the level of genetic diversity and LD in foxtail millet and its wild ancestor is very limited (Wang et al. 2010), which is necessary for dissecting DNA polymorphism underlying phenotypic variation using association mapping approach. To make use of foxtail millet core collection as association panel, the study was formulated to (i) examine the population structure of a foxtail millet core collection; (ii) investigate the genetic diversity within and among subpopulations (SP), and (iii) identify the extent of LD within core collection. Results of this study would provide valuable information for trait association mapping using foxtail millet core collection, effective germplasm conservation, genomic studies and breeding applications.

\section{Materials and methods}

\section{Plant materials}

A foxtail millet core collection consisting of 155 accessions, which is $10.51 \%$ of 1474 foxtail millet accessions from 23 countries conserved in ICRISAT genebank, was used (Upadhyaya et al. 2008). The collection consisted of 102 accessions $(65.8 \%)$ from the race 'indica', 24 accessions $(15.5 \%)$ from the race 'maxima' and 29 accessions $(18.7 \%)$ from the race 'moharia'.

Genotyping by simple sequence repeat (SSR) markers

The details of simple sequence repeat (SSR) genotyping are available elsewhere (Vetriventhan et al. 2012), which have been followed in the present investigation. DNA was extracted from the 20 days old seedlings of 155 accessions using a high-throughput mini-DNA extraction method (Mace et al. 2003). A total of 72 SSR markers located across nine chromosomes of foxtail millet were used (Jia et al. 2009). The forward primers of all the SSRs were synthesized by adding M13-forward primer sequence (5' CACGACGTTGT AAAACGAC $3^{\prime}$ ) at the $5^{\prime}$ end of each primer. Genomic DNA of all the accessions was normalized to a uniform concentration of $5 \mathrm{ng} \mu \mathrm{l}^{-1}$ and the PCR were performed in $5 \mu \mathrm{l}$ reaction. PCR products were then size-separated by capillary electrophoresis using an ABI Prism 3730xl DNA analyzer (Applied Biosystems Inc.). Raw data produced from ABI 3730xl DNA Analyser was analysed using Genemapper ${ }^{\circledR}$ software version 4.0 (Applied Biosystems, USA) and fragment size was scored in base pairs (bp) based on the relative migration of the internal size standard, LIZ 500 (Applied Biosystems, USA).

Population structure analysis

The model-based software program STRUCTURE 2.3.2 (Pritchard et al. 2000a, b) was employed to subdivide accessions into genetic SP. No prior information was used to define SP. To determine most appropriate $k$ value, burn-in Markov Chain Monte Carlo (MCMC) replication was set to 10,000 and data were collected over $1,00,000$ MCMC replications in each run. Five independent runs were performed setting the number of population (k) from 2 to 10 using a model allowing for no-admixture and correlated allele frequencies. The basis of this kind of clustering method is the allocation of individual genotypes to $k$ clusters in such a way that Hardy-Weinberg equilibrium and linkage equilibrium are valid within clusters, whereas these kinds of equilibrium are absent between clusters. The $k$ value was determined based on the rate of change in $\operatorname{LnP}(\mathrm{D})$ between successive $k$, stability of grouping pattern across five run and germplasm information about the material under study.

Allele number, gene diversity, polymorphic information content (PIC), and heterozygosity (\%) of each SP were calculated using PowerMarker version 3.25 (Liu and Muse 2005). An analysis of molecular variance (AMOVA) was performed based on 999 permutations using the software GENALEX 6.41 (Peakall and Smouse 2006) to estimate population differentiation among the SP. Furthermore, pairwise genetic 
distance (GD) (Nei 1972), $F_{S T}$ between SP and Shannon's information index $(I)$ were calculated using the software GENALEX 6.41. Pairwise Nei's GD and $F_{S T}$ indicates the GD between the populations, measure of the extent of genetic differentiation among SP. The low $F_{S T}$ and Nei's GD values between populations were indicative of minimal differentiation or high gene flow between the populations and vice versa. Principal coordinate analysis (PCoA) and neighborjoining phylogenetic analysis was conducted to further assess the population subdivisions. PCoA was performed based on Nei (1973) distance matrix using GENALEX 6.41 and neighbor-joining tree was constructed based on the simple matching dissimilarity as implemented in DARwin V.5.0.158 (2009-07-06) programme (Perrier and Jacquemoud-Collet 2006).

\section{Linkage disequilibrium (LD)}

The level of LD between pairs of locus was performed and the significance of pair-wise LD among all possible SSR loci was evaluated using TASSEL 2.1 (Bradbury et al. 2007) with the rapid permutation test in 10,000 shuffles. LD was estimated by squared allele-frequency correlations $\left(r^{2}\right)$ between pairs of SSR loci. The pair of loci was considered to be significant in LD if $P$ was $\leq 0.01$.

\section{Results}

Overall genetic diversity

Seventy-two SSRs detected a total of 1,202 alleles in the core collection. The average number of alleles per locus was 16.69 , ranging from 4 to 35 (Table 1 ). The mean gene diversity was 0.73 , and the mean PIC was 0.72. The average Shannon's information index was 1.99 , ranging from 0.78 to 3.14 . A total of 35 private or unique alleles that were present only in one accession and absent in the other accessions were detected. The average heterozygosity was 0.04 , close to $100 \%$ homozygosity.

Population structure and genetic diversity of subpopulations

As per the STRUCTURE analysis, the number of population was assumed to be four $(k=4)$ based on rate of change in $\operatorname{Ln} P(D)$ between successive $k$, stability of grouping pattern across five runs and germplasm information about the material under study (Fig. 1). Out of five runs for $k=4$, the run with highest likelihood value was selected to assign the posterior membership coefficient $(\mathrm{Q})$ to each accession. A graphical bar plot was then generated with the posterior membership coefficient (Fig. 2). The four SP as inferred in the STRUCTURE analysis were named as $\mathrm{SP}_{1}, \mathrm{SP}_{2}, \mathrm{SP}_{3}$ and $\mathrm{SP}_{4}$, respectively. Overall proportions of membership of the accessions in each of the four SP $\left(\mathrm{SP}_{1}\right.$ to $\left.\mathrm{SP}_{4}\right)$ were $0.365,0.045,0.058$ and 0.533 , respectively. $\mathrm{SP}_{1}$ contained 59 accessions and represented all three races, of which, moharia dominated with 27 accessions followed by maxima $(18$ accessions) and indica (14 accessions). $\mathrm{SP}_{2}$ consisted of four accessions; three belongs to race, maxima, while all the seven accessions in $\mathrm{SP}_{3}$ belong to indica race. Eighty-one of the 84 accessions in $\mathrm{SP}_{4}$ belong to race indica.

The genetic diversity was assessed for each SP (Table 1). $\mathrm{SP}_{1}$ had the highest gene diversity (0.80), number of alleles per locus (14.40), Shannon's information index (2.14) and population specific alleles (417) compared with other SP. Among 1,202 alleles detected in core collection, 1,037 alleles were found in $\mathrm{SP}_{1}, 180$ alleles in $\mathrm{SP}_{2}, 185$ alleles in $\mathrm{SP}_{3}$ and 728 alleles in $\mathrm{SP}_{4}$. $\mathrm{SP}_{1}$ had the highest populationspecific or private allele followed by $\mathrm{SP}_{4}$. Among the 1,037 alleles detected in $\mathrm{SP}_{1}, 417$ alleles were private alleles. A total of 13 private alleles in $\mathrm{SP}_{2}, 4$ in $\mathrm{SP}_{3}$ and 126 in $\mathrm{SP}_{4}$ were found. Sample size of $\mathrm{SP}_{1}$ is smaller than $\mathrm{SP}_{4}$, exhibited relatively high gene diversity. Eighty-one of the 84 accessions in $\mathrm{SP}_{4}$ belong to race indica of which 74 accessions were from India, showed the maximum gene diversity, PIC and allele number after $\mathrm{SP}_{1}$. Among 94 accessions from India, 74 accessions were grouped together under the $\mathrm{SP}_{4}$ and seven accessions were grouped under $\mathrm{SP}_{3}$. In total, among 155 accessions, 94 accessions are from India, 12 accessions from Sriya, seven accessions from Russia and CIS, six from China, five each from Korea and USA, and other countries are represented by less than three accessions (Table 2).

Assessment of population structure

The genetic relationship among the SP was measured by Nei's GD and pairwise estimate of $F_{S T}$ (Table 3). 
Table 1 Molecular diversity of SP detected by STRUCTURE using 72 SSR markers

\begin{tabular}{|c|c|c|c|c|c|}
\hline \multirow[t]{2}{*}{ Statistics } & \multirow[t]{2}{*}{ Overall } & \multicolumn{4}{|c|}{ SP detected by STRUCTURE software } \\
\hline & & $\mathrm{SP}_{1}$ & $\mathrm{SP}_{2}$ & $\mathrm{SP}_{3}$ & $\mathrm{SP}_{4}$ \\
\hline Sample size & 155 & 59 & 4 & 7 & 85 \\
\hline Total number of alleles & 1,202 & 1,037 & 180 & 185 & 728 \\
\hline Average number of alleles per locus & $16.69(4-35)^{\mathrm{a}}$ & $14.40(3-30)$ & $2.50(1-4)$ & $2.57(1-5)$ & $10.04(1-23)$ \\
\hline Standard error (SE) & 0.920 & 0.790 & 0.080 & 0.120 & 0.700 \\
\hline Shannon's information index $(I)$ & $1.99(0.78-3.14)$ & $2.14(0.38-3.25)$ & $0.80(0-1.21)$ & $0.70(0-1.55)$ & $1.14(0-2.28)$ \\
\hline SE & 0.092 & 0.005 & 0.037 & 0.048 & 0.095 \\
\hline Gene diversity & $0.73(0.06-0.95)$ & $0.80(0.16-0.96)$ & $0.50(0-0.75)$ & $0.41(0-0.78)$ & $0.63(0-0.93)$ \\
\hline SE & 0.026 & 0.022 & 0.021 & 0.027 & 0.032 \\
\hline Heterozygosity & $0.04(0-0.22)$ & $0.04(0-0.25)$ & $0.01(0-0.25)$ & $0.01(0-0.33)$ & $0.04(0-0.26)$ \\
\hline SE & 0.004 & 0.039 & 0.007 & 0.007 & 0.005 \\
\hline $\mathrm{PIC}^{\mathrm{b}}$ & $0.72(0.06-0.94)$ & $0.78(0.15-0.95)$ & $0.43(0-0.70)$ & $0.36(0-0.73)$ & $0.61(0-0.92)$ \\
\hline Population specific alleles number & 35 & 417 & 13 & 4 & 126 \\
\hline
\end{tabular}

${ }^{a}$ Values in parenthesis represents range

b PIC polymorphic information content

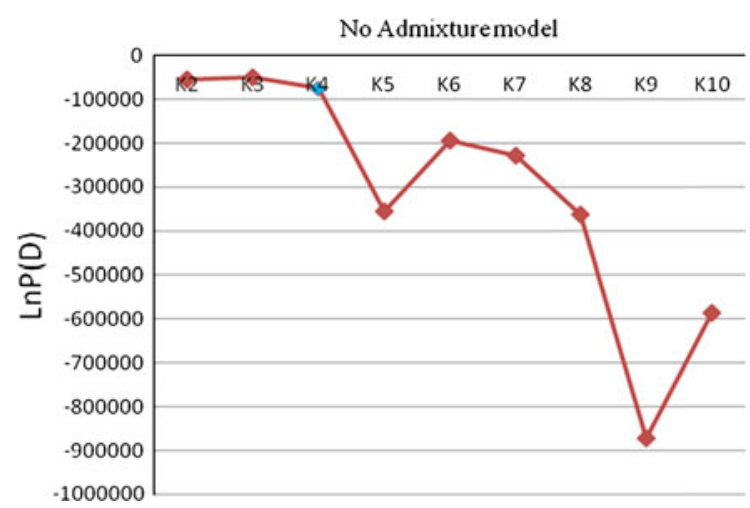

Fig. 1 Rate of change in $\operatorname{Ln} P(D)$ between successive $k$ ( $k$ averaged over the five run). $k$ ranged from 2 to 10

The pairwise $F_{S T}$ was the highest between $\mathrm{SP}_{2}$ and $\mathrm{SP}_{3}$ (0.385) followed by $\mathrm{SP}_{2}$ and $\mathrm{SP}_{4}$ (0.248). Pairwise estimates of $F_{S T}$ values were found to be significant between populations (Table 3), indicate the existence of significant genetic differentiation among SP. The GD data agreed with the $F_{S T}$ estimate. The $\mathrm{SP}_{3}$ showed the lowest GD with $\mathrm{SP}_{4}(0.256)$, and $\mathrm{SP}_{1}$ showed the lowest GD with $\mathrm{SP}_{4}(0.300)$ whereas, $\mathrm{SP}_{2}$ showed the greatest GD with $\mathrm{SP}_{3}$ (1.141) followed by $\mathrm{SP}_{2}$ with $\mathrm{SP}_{4}(0.842)$.

PCoA and the neighbor-joining phylogenetic analysis were performed to further assess the population subdivisions. In the PCoA, the first three PCos explained $66.9 \%$ variation, of which, $\mathrm{PCo} 1$ and $\mathrm{PCo} 2$ contributed
37.3 and $16.4 \%$, respectively of the SSR variation among the 155 accessions (Fig. 3a, b). Plotting the first two PCos and coding of genotypes according to three biological races of foxtail millet (Fig. 3a) shows clear separation of the race indica, most of which were present in $\mathrm{SP}_{4}$ (Fig. 2). The race maxima and moharia were not clearly separated as in $\mathrm{SP}_{1}$. Further, plotting the first two PCos and coding of genotypes according to the four SP identified using STRUCTURE shows the clear separation of four SP $\left(\mathrm{SP}_{1}\right.$ to $\left.\mathrm{SP}_{4}\right)$ (Fig. $3 \mathrm{~b}$ ). The neighborjoining tree of 155 core accessions and color coding of genotypes revealed that $\mathrm{SP}_{1}$ (Red) and $\mathrm{SP}_{4}$ (Blue) were the major $\mathrm{SP}$ along with two small SP, $\mathrm{SP}_{2}$ (Green) and $\mathrm{SP}_{3}$ (Black) (Fig. 4), fairly corresponded to STRUCTURE analysis. Further, AMOVA on the basis of SP and the three races of foxtail millet showed consistent relationship, representing high intra-population variation, which confirmed that the population has obvious structure (Table 4).

Linkage disequilibrium (LD)

The extent of LD was assessed among 2,556 marker pairs for all accessions. The $r^{2}$, the square of the correlation coefficient between two loci was used to measure LD. In a total of 2,556 pair wise comparisons (352 linked and 2,204 unlinked marker pairs) on the basis of 72 mapped SSR loci, 67, 53 and $39 \%$ of SSR marker pairs showed significant LD at $P \leq 0.05$, 


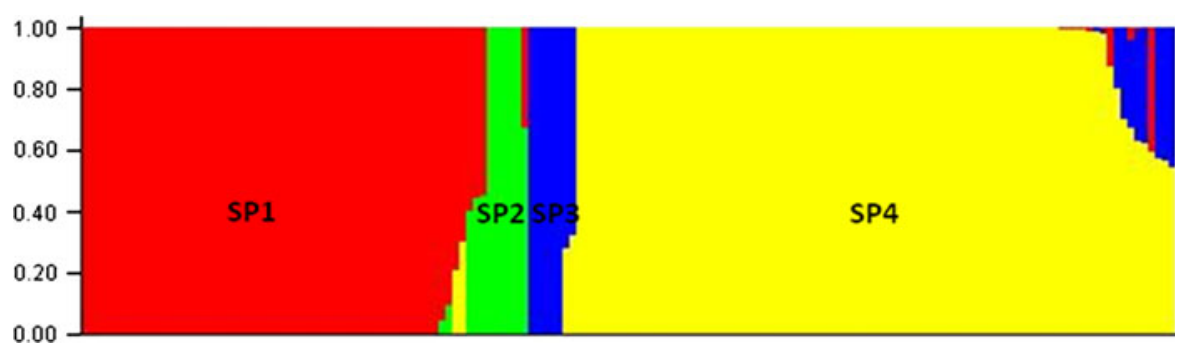

Fig. 2 Population structure of foxtail millet core collection based on 72 SSR markers. Numbers in the ' $y$ ' axis show the subgroup membership and each accession represented by thin

$P \leq 0.01$ and $P \leq 0.001$, respectively. At the whole population level, the $r^{2}$ ranged from 0.0008 to 0.19 and 1,430 pairs of loci were significant at $P \leq 0.01$. Scatter plot of the LD values based on the $r^{2}$ values of 155 accessions are shown in Fig. 5, where LD values for inter-chromosomal markers are compiled in a single file at $350 \mathrm{cM}$. Among the inter-chromosomal pairs, $r^{2}$ ranged from 0.01 to 0.17 . At intra-chromosome level, LD was very common for distances $40 \mathrm{cM}$.

\section{Discussion}

Genetic diversity of foxtail millet core collection

In this investigation, a foxtail millet core collection was characterized using 72 SSR markers. High level of polymorphism was observed for all the SSR loci. The average number of alleles per locus was 16.69. The number of alleles ranged from 4 to 35 , which was higher than the earlier reports in foxtail millet $(6.16$, Jia et al. 2009; 14.04, Liu et al. 2011; 2.4, Lin et al. 2012) and less than the Chinese foxtail millet landraces (6-47, Wang et al. 2012) and Chinese green foxtail millet (33.5, Jia et al. 2013a), illustrated that ICRISAT foxtail millet core collection contain high genetic diversity, which could provide valuable and important gene resources for foxtail millet breeding programs and for genomic study. Higher diversity reported in the 250 accession of Chinese foxtail millet (Wang et al. 2012) might be due to its larger size, represents $1 \%$ of foxtail millet kept in the Chinese National Gene Bank (CNGB), which is larger than foxtail millet conserved at ICRISAT, Patencheru, India. In comparison with that of foxtail millet landraces, Jia et al. (2013a) reported the higher alleles vertical line, which is partitioned into four colored segments that represent the individual membership to the SP. SP subpopulation. (Color figure online)

per locus in green foxtail millet, shows that, a large part of the genetic diversity in the wild gene pool was lost during domestication of foxtail millet and necessity for germplasm collection and protection of the wild relatives of crops (Jia et al. 2013a). Higher genetic diversity of germplasm is favorable for genetic marker development, construction of segregating population, functional gene cloning and association mapping and provides enriched gene resources for gene mining in the grass family (Wang et al. 2012). Compared with green foxtail millet, large part of the genetic diversity in the wild gene pool was lost during the domestication of foxtail millet. Average heterozygosity in the foxtail millet core collection was 0.04, which is less than earlier reports in foxtail millet and green millet (0.07-0.19) (Lin et al. 2012; Kumari et al. 2013; Jia et al. 2013a), which indicate that, the accessions used in the present study are very much close to inbred lines.

Population structure and relationship between population structure with racial classification and geographical distribution

Association mapping with diverse germplasm or wild populations can identify new superior alleles that were not captured by breeding practices and supports introgression of these alleles into elite breeding germplasm (Kumar et al. 2007). However, understanding population structure is essential to avoid spurious association between phenotype and genotype in association mapping (Pritchard et al. 2000b). A model based approach implemented in the software STRUCTURE is the most frequently used approach. In the present study STRUCTURE analysis revealed the existence of population subdivision and identified four SP in foxtail millet core collection. This population structure might be due to the 
Table 2 Details of the accessions present in each SP detected by STRUCTURE analysis

\begin{tabular}{|c|c|c|c|c|}
\hline \multirow[t]{2}{*}{ Country/SP } & \multicolumn{3}{|l|}{ Race } & \multirow[t]{2}{*}{ Total } \\
\hline & $\overline{\text { moharia }(27)^{\#}}$ & maxima (18) & indica (14) & \\
\hline \multicolumn{5}{|c|}{$\mathrm{SP}_{1}$ : Total 59 accessions } \\
\hline Afghanistan & 2 & - & - & 2 \\
\hline China & - & 5 & - & 5 \\
\hline Hungary & 1 & - & - & 1 \\
\hline India & 1 & 3 & 7 & 11 \\
\hline Iran & 1 & - & - & 1 \\
\hline Korea & - & 4 & - & 4 \\
\hline Lebanon & 3 & - & - & 3 \\
\hline Malawi & - & - & 1 & 1 \\
\hline Nepal & - & 1 & - & 1 \\
\hline Pakistan & 2 & - & - & 2 \\
\hline Russia and CIS & 4 & 2 & - & 6 \\
\hline Spain & 1 & - & - & 1 \\
\hline Sri Lanka & - & - & 1 & 1 \\
\hline Syria & 7 & 1 & 3 & 11 \\
\hline Taiwan & 1 & 1 & 1 & 3 \\
\hline Turkey & 1 & 1 & - & 2 \\
\hline United Kingdom & - & - & 1 & 1 \\
\hline USA & 2 & - & - & 2 \\
\hline Unknown & 1 & - & - & 1 \\
\hline \multirow[t]{2}{*}{ Country/SP } & \multicolumn{3}{|l|}{ Race } & \multirow[t]{2}{*}{ Total } \\
\hline & maxima (3) & indica (1) & $\overline{\text { moharia }}$ & \\
\hline \multicolumn{5}{|c|}{$\mathrm{SP}_{2}:$ Total 4 accessions } \\
\hline India & 1 & 1 & - & 2 \\
\hline Korea & 1 & - & - & 1 \\
\hline Russia and CIS & 1 & - & - & 1 \\
\hline \multirow[t]{2}{*}{ Country/SP } & \multicolumn{3}{|l|}{ Race } & \multirow[t]{2}{*}{ Total } \\
\hline & indica $(7)$ & maxima & moharia & \\
\hline \multicolumn{5}{|c|}{$\mathrm{SP}_{3}:$ Total 7 genotypes } \\
\hline India & 7 & - & - & 7 \\
\hline \multirow[t]{2}{*}{ Country/SP } & \multicolumn{3}{|l|}{ Race } & \multirow[t]{2}{*}{ Total } \\
\hline & indica $(81)$ & moharia (2) & $\overline{\operatorname{maxima}(2)}$ & \\
\hline \multicolumn{5}{|c|}{$\mathrm{SP}_{4}:$ Total 85 accessions } \\
\hline China & 1 & - & - & 1 \\
\hline Ethiopia & 1 & - & - & 1 \\
\hline India & 71 & 2 & 1 & 74 \\
\hline Kenya & 1 & - & - & 1 \\
\hline Malawi & 1 & - & - & 1 \\
\hline Nepal & 0 & - & 1 & 1 \\
\hline Pakistan & 1 & - & - & 1 \\
\hline
\end{tabular}


Table 2 continued

\begin{tabular}{|c|c|c|c|c|}
\hline \multirow[t]{2}{*}{ Country/SP } & \multicolumn{3}{|l|}{ Race } & \multirow[t]{2}{*}{ Total } \\
\hline & indica (81) & moharia (2) & maxima (2) & \\
\hline South Africa & 1 & - & - & 1 \\
\hline Syria & 1 & - & - & 1 \\
\hline USA & 3 & - & - & 3 \\
\hline
\end{tabular}

\# Numbers in parenthesis indicate number of accessions in each group

Table 3 Pairwise estimates of Nei's GD and $F_{S T}$ among the four SP detected by STRUCTURE

\begin{tabular}{lllll}
\hline $\mathrm{SP}$ & $\mathrm{SP}_{1}$ & $\mathrm{SP}_{2}$ & $\mathrm{SP}_{3}$ & $\mathrm{SP}_{4}$ \\
\hline $\mathrm{SP}_{1}$ & & 0.557 & 0.550 & 0.300 \\
$\mathrm{SP}_{2}$ & $0.126^{* *}$ & & 1.141 & 0.842 \\
$\mathrm{SP}_{3}$ & $0.172^{* *}$ & $0.385 * *$ & & 0.256 \\
$\mathrm{SP}_{4}$ & $0.100^{* *}$ & $0.248 * *$ & $0.139 * *$ &
\end{tabular}

$F_{S T}$ estimate appear below the diagonal $(* *$ significant at $P \leq 0.01)$ and pairwise Nei's GD appears above the diagonal

presence of three races of foxtail millet, indica, maxima and moharia. The total number of alleles, number of alleles per locus, $\mathrm{PIC}$ and gene diversity was more in $\mathrm{SP}_{1}$ and $\mathrm{SP}_{4}$, which can be explained by the difference in the sample size and diversity within the SP, which can lead to differential allelic richness (Yang et al. 2010). Sample size of $\mathrm{SP}_{1}$ is smaller than $\mathrm{SP}_{4}$, exhibited relatively high gene diversity, and is due to presence of all three races from different geographic regions.

The 155 accessions of the foxtail millet core collection were from 23 countries, with the majority being from India, and a few accessions were from other countries, we did not obtain a clear-cut grouping of the accessions based on either countries or regions of origin. However, the population subdivisions detected through STRUCTURE, PCoA and neighbor-joining phylogenetic analysis, $F_{S T}$ and GD were in accordance with racial classification of foxtail millet. Eighty-one of the 84 accessions in $\mathrm{SP}_{4}$ belong to race indica of which 74 accessions were from India, showed the maximum gene diversity, PIC and allele number after $\mathrm{SP}_{1}$ suggesting that, there is lot of genetic variation in foxtail millet germplasm collected from India. The distribution of molecular genetic variation among and within the four SP and three races revealed high degree of variability within each group, and low level of GD among the groups. This results in agreement with earlier study in foxtail millet (Wang et al. 2012) and other crops (Abdurakhmonov and Abdukarimov 2008; Peleg et al. 2008a, b; Jun et al. 2008).

Linkage disequilibrium (LD) in ICRISAT foxtail millet core collection

Foxtail millet, as a self-pollinating species, is expected to have a high level of LD (Wang et al. 2012). Wang et al. (2010) reported the increased level of LD in the domesticated foxtail millet (extends to $1 \mathrm{~kb}$ ), while it decayed rapidly to a negligible level within $150 \mathrm{bp}$ in wild green foxtail, suggested that, the increased level of LD in the cultivated foxtail millet was mainly due to the change of population size during the domestication process. Wang et al. (2012) reported the LD decay of less than $20 \mathrm{cM}$ of GD using SSR markers with 250 foxtail millet landraces. In self-pollinating crops such as barley, LD commonly extends for distances of up to $10 \mathrm{cM}$ (Kraakman et al. 2004), and in some Arabidopsis populations, LD exceeds $50 \mathrm{cM}$ (Nordborg et al. 2002). LD is high in rice, and LD decay values are 20-30 cM (Agrama et al. 2007). In our study, LD decay of $\sim 40 \mathrm{cM}$ of GD was observed, which suggests that it could be possible to achieve resolution down to the $40 \mathrm{cM}$ level.

The choice of germplasm is a key factor which determines the resolution of AM. The core collection, which represents the diversity of the entire collection of that species, would be the ideal material for association mapping (Whitt and Buckler 2003). The core collection was effectively used as association mapping panel in several crops viz, rice (Borba et al. 2010), wheat (Dodig et al. 2012), sorghum (Shehzad et al. 2009; Upadhyaya et al. 2012a, b), common bean (Blair et al. 2009) etc. Availability of huge number of molecular markers in foxtail millet (Jia et al. 2009; Kumari et al. 2013; Pandey et al. 2013; Muthamilarasan et al. 2013) 
Fig. 3 PCoA of foxtail millet core collection accessions using 72 SSR markers based on Nei (1973) distance estimates. PCo1 and $\mathrm{PCo} 2$ are the first and the second principal coordinates, respectively. Numbers in parentheses refers to the proportion of variance explained by the principal coordinate. $S P$ subpopulation. a PCoA: coding based on three biological races. b $\mathrm{PCOA}$ : coding based on four SP identified in STRUCTURE analysis (a) PCoA: coding based on three biological races

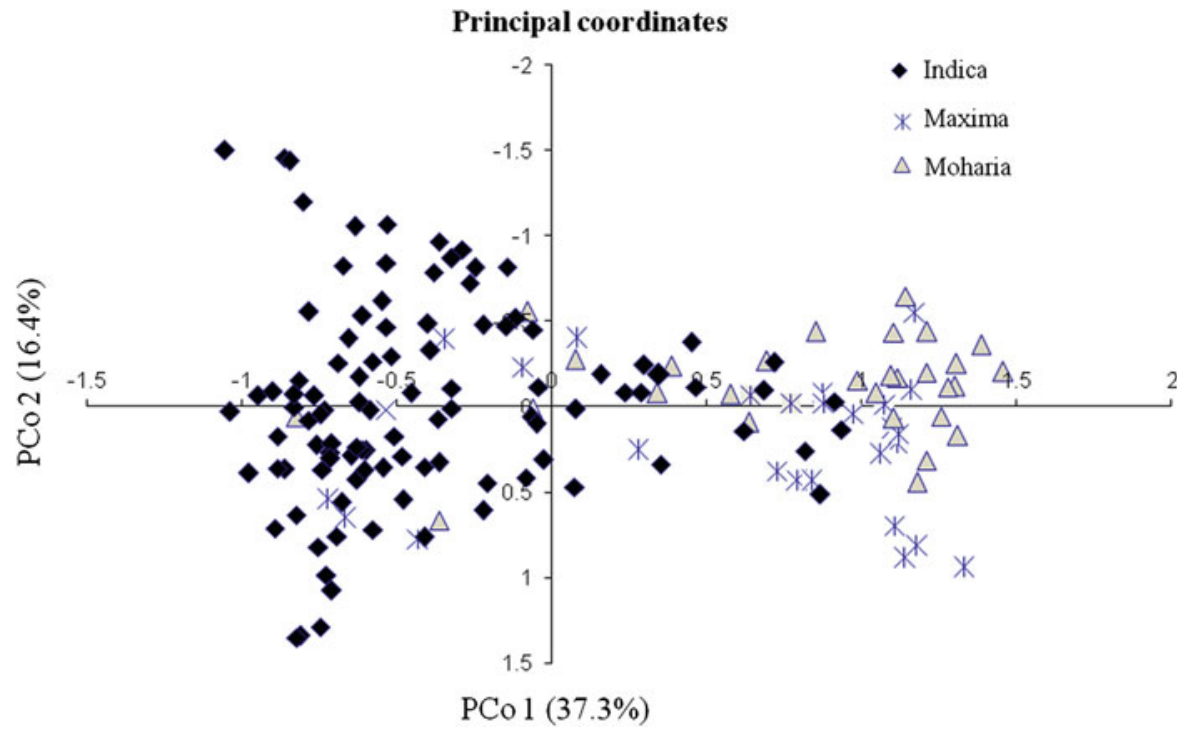

(b) PCoA: coding based on four subpopulations identified in STRUCTURE analysis

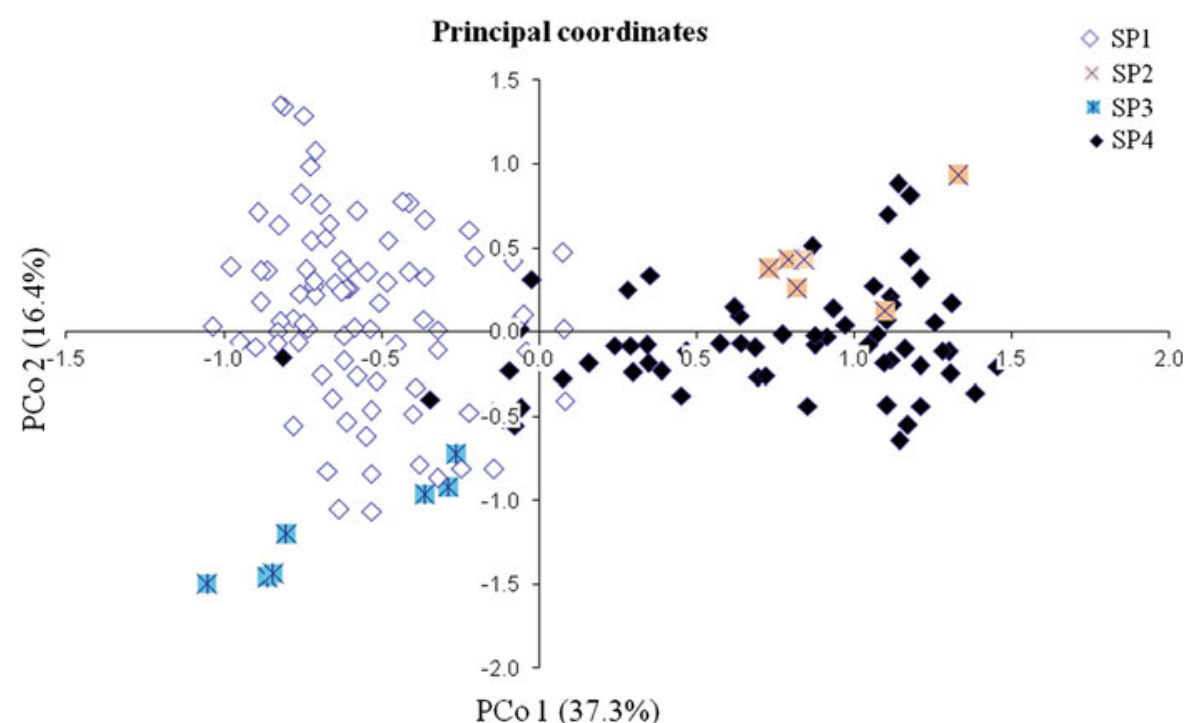

provides an immense applicability in germplasm characterization, phylogenetics, gene/quantitative trait loci discovery and comparative mapping. It is now possible to do genome-wide association mapping. Pandey et al. (2013) identified 28,342 microsatellite repeat-motifs spanning $405.3 \mathrm{Mb}$ of foxtail millet genome, of the 28,342 microsatellites, 21,294 primer pairs were successfully designed, and a total of 15,573 markers were physically mapped on 9 chromosomes of foxtail millet. Muthamilarasan et al. (2013) developed 5,123 intronlength polymorphic (IPL) markers of which 4049 were physically mapped onto 9 chromosomes of foxtail millet. Jia et al. (2013b) sequenced 916 diverse foxtail millet varieties, identified 2.58 million SNPs and used 0.8 million common SNPs to construct a haplotype map of the foxtail millet genome. Also phenotyped the 916 diverse foxtail millet under five different environments and identified 512 loci associated with 47 agronomic traits by genome-wide association studies.

The phenotypic variations of many complex traits of agronomic importance are influenced by genotype and genotype $\times$ environment interaction; hence 
Fig. 4 Neighbor-joining tree based on the simple matching dissimilarity matrix of 72 markers genotyped across the foxtail millet core collection. Each color represents the different SP identified in STRUCTURE analysis. Red $\mathrm{SP}_{1}$, Green $\mathrm{SP}_{2}$, Black $\mathrm{SP}_{3}$, Blue $\mathrm{SP}_{4}$. (Color figure online)

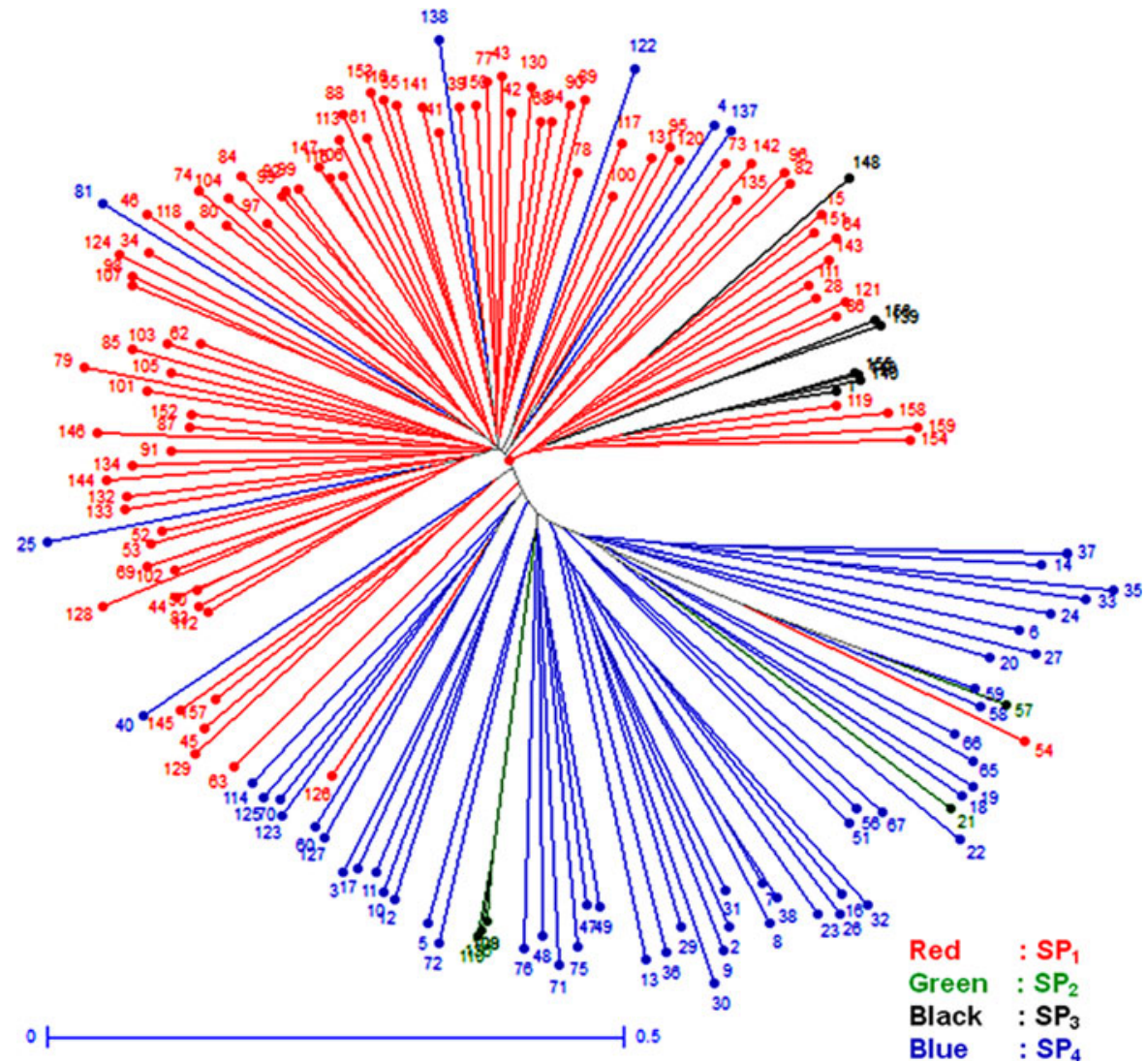

Table 4 AMOVA based on four SP $\left(\mathrm{SP}_{1}\right.$ to $\left.\mathrm{SP}_{4}\right)$ detected by STRUCTURE and three races in the foxtail millet core collection

\begin{tabular}{|c|c|c|c|c|c|}
\hline Source & df & $\begin{array}{l}\text { Sum of } \\
\text { square }\end{array}$ & $\begin{array}{l}\text { Mean sum } \\
\text { of square }\end{array}$ & $\begin{array}{l}\text { Estimated } \\
\text { variance }\end{array}$ & $\begin{array}{l}\text { Percentage of } \\
\text { variation }(\%)\end{array}$ \\
\hline \multicolumn{6}{|c|}{ Based on SP inferred by STRUCTURE } \\
\hline Among populations & 3 & $1,250.3$ & 416.8 & 11.1 & 10 \\
\hline Within population & 151 & $15,060.7$ & 99.7 & 99.7 & 90 \\
\hline Total & 154 & $16,311.0$ & & 110.9 & \\
\hline \multicolumn{6}{|c|}{ Based on three races viz., indica, maxima and moharia } \\
\hline Among populations & 2 & 818.48 & 409.24 & 7.81 & 7 \\
\hline Within population & 152 & $15,495.80$ & 101.95 & 101.95 & 93 \\
\hline Total & 154 & $16,314.28$ & & 109.75 & \\
\hline
\end{tabular}

replicated multi-environment testing is prerequisite and useful for correctly identifying QTLs associated with the trait of interest (Tao et al. 2000). This core collection is manageable in size (155 accessions), represents diversity of 1,474 foxtail millet accessions, can be extensively evaluated under replicated multi-environments for various economically important traits of interest, using relatively less resources. Availability of large number molecular markers in foxtail millet (Jia et al. 2009; Kumari et al. 2013; Pandey et al. 2013; Muthamilarasan et al. 2013), can be used to identify marker trait association using this core collection as an association panel. 


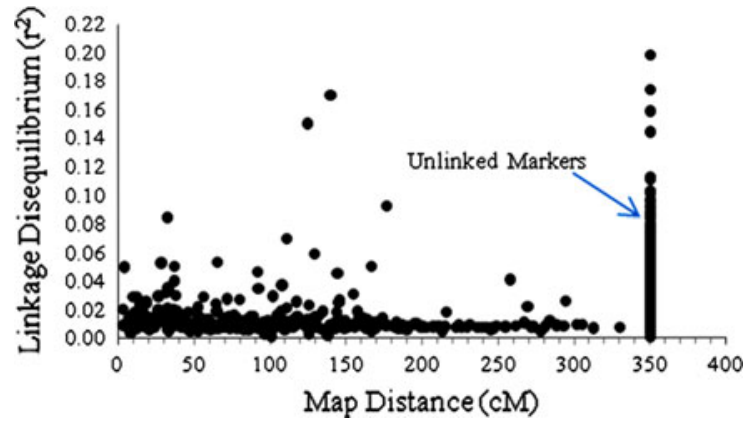

Fig. 5 The pattern of LD for 72 SSR loci indicating correlations of allele frequency $\left(r^{2}\right)$ value against GD (cM) between all loci pairs

Acknowledgments The authors gratefully acknowledge the financial support of the BMZ/GTZ project on "Sustainable conservation and utilization of genetic resources of two underutilized crops-finger millet and foxtail millet- to enhance productivity, nutrition and income in Africa and Asia" funded by the Federal Ministry for Economic Cooperation and Development (BMZ), Germany to carry out this activity.

\section{References}

Abdurakhmonov IY, Abdukarimov A (2008) Application of association mapping to understating the genetic diversity of plant genetic resources. Int $\mathbf{J}$ Plant Genomics. doi:10. $1155 / 2008 / 574927$

Agrama HA, Eizenga GC, Yan W (2007) Association mapping of yield and its components in rice cultivars. Mol Breed 19:341-356

Austin DF (2006) Foxtail millets (Setaria: Poaceae)-abandoned food in two hemispheres. Econ Bot 60:143-158

Barton L, Newsome SD, Fa-Hu Chen, Wang H, Guilderson TP, Bettinger RL (2009) Agricultural origins and the isotopic identity of domestication in northern China. PNAS 106:5523-5528

Bennetzen JL, Schmutz J, Wang H et al (2012) Reference genome sequence of the model plant Setaria. Nat Biotechnol 30:555-561

Blair MW, Díaz LM, Buendía HF, Duque MC (2009) Genetic diversity, seed size associations and population structure of a core collection of common beans (Phaseolus vulgaris L.). Theor Appl Genet 119:955-972

Borba TCO, Brondani RPV, Breseghello F, Coelho ASG, Mendonça JA, Rangel PHN, Brondani C (2010) Association mapping for yield and grain quality traits in rice (Oryza sativa L.). Genet Mol Biol 33:515-524

Bradbury PJ, Zhang Z, Kroon DE, Casstevens TM, Ramdoss Y, Buckler ES (2007) TASSEL: software for association mapping of complex traits in diverse samples. Bioinformatics 23:2633-2635

Dodig D, Zoric M, Kobiljski B, Savic J, Kandic V, Quarrie S, Barnes J (2012) Genetic and association mapping study of wheat agronomic traits under contrasting water regimes. Int J Mol Sci 13:6167-6188
Doust AN, Kellogg EA, Devos KM, Bennetzen JL (2009) Foxtail millet: a sequence driven grass model system. Plant Physiol 149:137-141

Flint-Garcia SA, Thuillet AC, Yu JM, Pressoir G, Romero SM, Mitchell SE, Doebley J, Kresovich S, Goodman MM, Buckler ES (2005) Maize association population: a highresolution platform for quantitative trait locus dissection. Plant J 44:1054-1064

Frankel OH (1984) Genetic perspective of germplasm conservation. In: Arber W, Illmensee K, Peacock WJ, Starlinger P (eds) Genetic manipulations: impact of man and society. Cambridge University Press, Cambridge, pp 161-170

Hirano R, Naito K, Fukunaga K, Watanabe KN, Ohsawa R, Kawase M (2011) Genetic structure of landraces in foxtail millet (Setaria italica (L.) P. Beauv.) revealed with transposon display and interpretation to crop evolution of foxtail millet. Genome 54:498-506

Holland JB (2007) Genetic architecture of complex traits in plants. Curr Opin Plant Biol 10:156-161

Jia X, Zhang Z, Liu Y, Zhang C, Shi Y, Song Y, Wang T, Li Y (2009) Development and genetic mapping of SSR markers in foxtail millet (Setaria italica (L.) P. Beauv.). Theor Appl Genet 118:821-829

Jia G, Shi S, Wang C, Niu Z, Chai Y, Zhi H, Diao X (2013a) Molecular diversity and population structure of Chinese green foxtail [Setaria viridis (L.) Beauv.] revealed by microsatellite analysis. J Exp Bot 64:3645-3655

Jia G, Huang X, Zhi H, Zhao Y et al (2013b) A haplotype map of genomic variations and genome-wide association studies of agronomic traits in foxtail millet (Setaria italica). Nat Genet 45:957-961

Jun TH, Van K, Kim MY, Lee SH, Walker DR (2008) Association analysis using SSR markers to find QTL for seed protein content in soybean. Euphytica 162:179-191

Kihara H, Kishimoto E (1942) Bastrade zwischen Setaria italica und $S$. viridis. (in Japanese with German summary). Bot Mag Tokyo 56:62-67

Kraakman ATW, Niks RE, Van Den Berg PMMM, Stam P, Van Eeuwijk FA (2004) Linkage disequilibrium mapping of yield and yield stability in modern spring barley cultivars. Genetics 168:435-446

Kruglyak L (1999) Prospects for whole-genome linkage disequilibrium mapping of common disease genes. Nat Genet 22:139-144

Kumar R, Qiu J, Joshi T, Valliyodan B, Xu D, Nguyen HT (2007) Single feature polymorphism discovery in rice. PLoS One 2:e284

Kumari K, Muthamilarasan M, Misra G, Gupta S, Subramanian A, Parida SK, Chattopadhyay D, Prasad M (2013) Development of eSSR-Markers in Setaria italica and their applicability in studying genetic diversity, cross-transferability and comparative mapping in millet and non-millet species. PLoS One 8(6):e67742. doi:10.1371/journal.pone. 0067742

Li P, Brutnell TP (2011) Setaria viridis and Setaria italica, model genetic systems for the panicoid grasses. J Exp Bot 62:3031-3037

Li HW, Li CH, Pao WK (1945) Cytological and genetical studies of the interspecific cross of cultivated foxtail millet, Setaria italica (L.) Beauv., and the green foxtail millet, $S$. viridis (L.). J Am Soc Agron 37:32-54 
Lin HS, Liao GI, Chiang CY, Kuoh CS, Chang SB (2012) Genetic diversity in the foxtail millet (Setaria italica) germplasm as determined by agronomic traits and microsatellite markers. Aust J Crop Sci 6(2):342-349

Liu K, Muse SV (2005) Powermarker: an integrated analysis environment for genetic marker data. Bioinformatics 21:2128-2129

Liu L, Wang L, Yao J, Zhang Y, Zhao C (2010) Association mapping of six agronomic traits on chromosome 4A of wheat (Triticum aestivum L.). Mol Pl Breed 1(5):10

Liu Z, Bai G, Zhang D, Znu C, Xia X, Cheng Z, Shi Z (2011) Genetic diversity and population structure of elite foxtail millet (Setaria italica (L.) P. Beauv.) germplasm in China. Crop Sci 51:1655-1663

Lu H, Zhang J, Liu KB, Wu N, Li Y, Zhou K, Ye M, Zhang T, Zhang H, Yang X, Shen L, Xu D, Li Q (2009) Earliest domestication of common millet (Panicum miliaceum) in East Asia extended to 10,000 years ago. PNAS 106:7367-7372

Mace ES, Buhariwalla HK, Crouch JH (2003) A highthroughput DNA extraction protocol for tropical molecular breeding programs. Plant Mol Biol Repor 21:459a-459h

Malosetti M, van der Linden CG, Vosman B, van Eeuwijk FA (2007) A mixed-model approach to association mapping using pedigree information with an illustration of resistance to Phytophthora infestans in potato. Genetics 175:879-889

Murray SC, Rooney WL, Hamblin MT, Mitchell SE, Kresovich S (2009) Sweet sorghum genetic diversity and association mapping for brix and height. Plant Genome 2:48-62

Muthamilarasan M, Venkata Suresh B, Pandey G, Kumari K, Kumar Parida S, Prasad M (2013) Development of 5123 intron-length polymorphic markers for large-scale genotyping applications in foxtail millet. DNA Res. doi:10. 1093/dnares/dst039

Nei M (1972) Genetic distance between populations. Am Nat 106:283-392

Nei M (1973) Analysis of gene diversity in subdivided populations. PNAS 70:3321-3323

Neumann K, Kobiljski B, Denčić S, Vershney RK, Börner A (2011) Genome-wide association mapping: a case study in bread wheat (Triticum aestivum L.). Mol Breed 27:37-58

Nordborg M, Borevitz JO, Bergelson J, Berry CC, Chory J, Hagenblad J, Kreitman M, Maloof JN, Noyes T, Oefner PJ, Stahl EA, Weigel D (2002) The extent of linkage disequilibrium in Arabidopsis thaliana. Nat Genet 30:190-193

Pandey G, Misra G, Kumari K, Gupta S, Parida SK, Chattopadhyay D, Prasad M (2013) Genome-wide development and use of microsatellite markers for large-scale genotyping applications in foxtail millet [Setaria italica (L.)]. DNA Res 20:197-207

Peakall R, Smouse PE (2006) GENALEX 6: genetic analysis in Excel. Population genetic software for teaching and research. Mol Ecol Notes 6(1):288-295

Peleg Z, Fahima T, Abbo S, Krugman T, Saranga Y (2008a) Genetic structure of wild emmer wheat populations as reflected by transcribed versus anonymous SSR markers. Genome 51:187-195

Peleg Z, Saranga Y, Krugman T, Abbo S, Nevo E, Fahima T (2008b) Allelic diversity associated with aridity gradient in wild emmer wheat populations. Plant Cell Environ 31:39-49
Perrier X and Jacquemoud-Collet JP (2006) DARwin software (2006) http://darwin.cirad.fr/darwin

Prasada Rao KE, de Wet JMJ, Brink DK, Mengesha MH (1987) Intraspecific variation and systematics of cultivated Setaria italica, foxtail millet (Poaceae). Econ Bot 41:108-116

Pritchard JK, Stephens M, Rosenberg NA, Donnelly P (2000a) Association mapping in structured populations. Am J Hum Genet 67:170-181

Pritchard JK, Stephens M, Donnelly P (2000b) Inference of population structure using multilocus genotype data. Genetics 155:945-959

Remington DL, Thornsberry JM, Matsuoka Y, Wilson LM, Whitt SR, Doebley J, Kresovich S, Goodman MM, Buckler ES IV (2001) Structure of linkage disequilibrium and phenotypic associations in the maize genome. PNAS 98:11479-11484

Shehzad T, Iwata H, Okuno K (2009) Genome-wide association mapping of quantitative traits in sorghum (Sorghum bicolor (L.) Moench) by using multiple models. Breed Sci 59:217-227

Stich B, Melchinger AE, Frisch M, Maurer HP, Heckenberger M, Reifl JC (2005) Linkage disequilibrium in European elite maize germplasm investigated with SSRs. Theor Appl Genet 111:723-730

Tao YZ, Henzell RG, Jordan DR, Butler DG, Kelly AM, McIntyre CL (2000) Identification of genomic regions associated with stay green in sorghum by testing RILs in multiple environments. Theor Appl Genet 100:1225-1232

Upadhyaya HD, Ortiz R (2001) A mini core subset for capturing diversity and promoting utilization of chickpea genetic resources in crop improvement. Theor Appl Genet 102:1292-1298

Upadhyaya HD, Pundir RPS, Gowda CLL, Reddy VG, Singh S (2008) Establishing a core collection of foxtail millet to enhance utilization of germplasm of an underutilized crop. Plant Genet Resour 7:177-184

Upadhyaya HD, Yi-Hong Wang, Shivali Sharma, Singh S (2012a) Association mapping of height and maturity across five environments using sorghum mini core collection. Genome 55:471-479

Upadhyaya HD, Yi-Hong Wang, Shivali Sharma, Singh S, Hasenstein KH (2012b) SSR markers linked to kernel weight and tiller number in sorghum identified by association mapping. Euphytica 187:401-410

Vetriventhan M, Upadhyaya HD, Anandakumar CR, Senthilvel S, Parzies HK, Bharathi A, Varshney RK, Gowda CLL (2012) Assessing genetic diversity, allelic richness and genetic relationship among races in ICRISAT foxtail millet core collection. Plant Genet Resour 10:214-223

Wang R, Yu Y, Zhao J, Shi Y, Song Y, Wang T, Li Y (2008) Population structure and linkage disequilibrium of a mini core set of maize inbred lines in China. Theor Appl Genet 117:1141-1153

Wang C, Chen J, Zhi H, Yang L, Li W, Wang Y, Li H, Zhao B, Chen M, Diao X (2010) Population genetics of foxtail millet and its wild ancestor. BMC Genet 11:90

Wang C, Jia G, Zhi H, Niu Z, Chai Y, Li W, Wang Y, Li H, Lu P, Zhao B, Diao X (2012) Genetic diversity and population structure of Chinese foxtail millet [Setaria italica (L.) Beauv.] landraces. Gene Genome Genet 2:769-777 
Wen W, Mei H, Feng F, Yu S, Huang Z, Wu J, Chen L, Xu X, Luo L (2009) Population structure and association mapping on chromosome 7 using a diverse panel of Chinese germplasm of rice (Oryza sative L.). Theor Appl Genet 119:459-470

Whitt SR, Buckler ES (2003) Using natural allelic diversity to evaluate gene function. Methods Mol Biol 236:123-139

Yang X, Yan J, Shah T, Warburton ML, Li Q, Li L, Chai YG, Fu Z, Zhou Y, Xu S, Bai G, Meng Y, Zheng Y, Li J (2010) Genetic analysis and characterization of a new maize association mapping panel for quantitative trait loci dissection. Theor Appl Genet 121:417-431

Yu J, Buckler ES (2006) Genetic association mapping and genome organization of maize. Curr Opin Biotech 17:155-160

Zhang P, Li J, Li X, Liu X, Zhao X, Lu Y (2011) Population structure and genetic diversity in a rice core collection
(Oryza sativa L.) investigated with SSR markers. PLoS One 6:e27565

Zhang G, Liu X, Quan Z et al (2012) Genome sequence of foxtail millet (Setaria italica) provides insights into grass evolution and biofuel potential. Nat Biotech 30:549-554

Zhao K, Aranzana MJ, Kim S, Lister C, Shindo C, Tang C, Toomajian C, Zheng H, Dean C, Marjoram P, Nordborg M (2007) An Arabidopsis example of association mapping in structured samples. PLoS Genet 3(1):e4

Zhu CS, Gore M, Buckler ES, Yu JM (2008) Status and prospects of association mapping in plants. Plant Genome $1: 5-20$ 